by the area boards. Mr. J. H. Osborn suggested that the Ministry, the Central Electricity Generating Board, and the Atomic Energy Authority might survey the variety of pressurized water reactors, and asked whether the virtues of a boiling-water and similar types of reactor for smaller power stations were being considered. The achievement of the Atomic Energy Authority in developing the advanced gas reactor was welcomed in the debate. Mr. Osborn and also Mr. E. Lubbock and Mr. P. Jenkin were critical of its comparative cost compared with that of the boiling-water reactor developed in the United States at
Oyster Creek: this, it was said, could produce electricity at $0.34 d$. per unit. These and other speakers in the debate repeatedly stressed the importance of research. In replying on the debate, Mr. J. Morris, the Parliamentary Secretary to the Ministry of Power, said that the Minister was satisfied with the programmes to date and referred to the greater co-operation and co-ordination recently established between the gas, electricity and coal industries. As regards Oyster Creek, he said that this was not a comparison of like with like, and the Dungeness tenders were all competitive under British conditions.

\title{
BRITISH RESEARCH AND DEVELOPMENT IN TECHNOLOGY
}

N a written answer in the House of Commons on July 27, 1 Mr. F. Cousins, the Minister of Technology, said that the National Research Development Corporation was making available funds in support of programmes and projects of research and development by various firms in the computer industry. His Department would continue to support the industry by sharing the cost of contracts under the Advanced Computer Techniques Programme, involving additional commitments by the Government of about $£ 500,000$ in $1965-66$ and through contracts with universi-

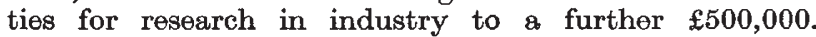
Arrangements had been made with the Minister of Housing and Local Government to bring the Computer Advisory Service to the notice of local authorities. Twenty-three British and six American computers were on order for Government departments, including the General Post Office; 12 computers of American design and foreign manufacture were in use in Government departments, and 58 in the nationalized industries. Eighty computers manufactured in Britain were in use in Government departments and 66 in the nationalized industries. A collaborative programme between the Atomic Energy Authority and industry on the desalination of sea-water was under way and a design study for a 30-Mgal./day plant, using flash distillation techniques, had been completed in conjunction with Weir, Westgarth, Ltd.

Mr. Cousins said that he had appointed Dr. J. B. Adams to be controller in the Ministry of Technology with effect from July 12, and that Dr. Adam would be in charge of all the scientific and technological work of the industry. An organization chart for the Ministry of Technology was published in the Official Report for July 27, and the responsibilities of the Economics and Statistics Division were listed in detail. This Division is organized in four branches: (1) Economics Branch, responsible for advising on the economics aspects of the Ministry's policies and programmes. This Branch provides support for the studies of industries conducted by the technological appraisal groups within the Ministry. (2) Statistics Branch, which is responsible for collating, analysing and interpreting statistics of industries for which the Ministry has sponsoring functions. These statistics are collected for the Ministry by the Board of Trade. (3) Manpower
Branch, which is concerned with manpower resources for science and technology and keeps under review the human and social problems resulting from technological change. (4) Engineering Branch, which has the main function of initiating or encouraging action to enhance the status of engineers and to improve the supply. It is also responsible for co-ordinating the implementation of the recom. mendations of the Fielden Report on Engineering Design.

Mr. Cousins also stated that the Ministry communicated technological information by personal contact, scientific and technical publications, exhibitions, conferences, press, film, radio and television, and was building up a network of regional offices and industrial liaison centres to supplement this effort. The Ministry's laboratories dealt with about 2,500 enquiries each month, mainly from industry. Much information was being received from scientific counsellors in foreign countries. The Department was undertaking a technical and economic study of the scientific industrial process-control instrument industry, and had initiated studies of engineering standards, the metric system and the industrial use of new materials. Also contained in the Official Report for July 27 was a full list of the leaders of the various scientific and technological teams studying selected industries and processes, with their date of appointment and relevant experience.

On July 27, replying to a question regarding the Advisory Council on Technology in the House of Lords, Lord Snow, the Parliamentary Secretary to the Ministry, said that the Council had met ten times; its terms of reference were to advise on the application of advanced technology in British industry and to give special attention to the industries for which the Minister had sponsorship responsibility. Among subjects considered have been the status of engineers and designers, development of British standards for export markets, the promotion of the metric system and problems of industrial structure. The relations between the Council for Scientific Policy and the Advisory Council on Technology were close and there was common membership. Lord Snow thought that there was no danger of any serious lacuna between them. Relations between the Ministry and the Department of Economic Affairs must also be close and he thought there was little danger of overlapping.

\section{THE MELLON INSTITUTE}

\begin{abstract}
HE fifty-second annual report of the Mellon Institute * covers the year ended February 28, 1965, at the close of which the staff of 539 included 355 professional and technical members. A list of visitor's' lectures at colloquia is apponded, and another of members' publications during the year. The brief accounts of research investigations

* Mellon Institute. Fifty-second Annual Report for the Fiscal Year ended February 28, 1965. Pp. 40. (Pittsburgh: Mellon Institute, 1965.)
\end{abstract}

during the year refer, under biochemistry and molecular biology, to improvements in instrument design and experimental procedures which have given a precision of $0 \cdot 2-0 \cdot 3$ per cent in determining sedimentation coefficients in examining structural transformations in Bromegrass mosaic virus, while further electron microscopical studies of actomyosin have confirmed the identification of 'ladders' as the principal morphological form of con- 
tractile suspensions. Visible light shadows of a model of part of the tropocollagen macromolecule, made from foam plastic atomic models, with one or more of the three strands broken indicate that electron microscopy should detect collagenase activity on tropocollagen.

Environmental investigations have been concerned with the purification of the atmosphere, the electrokinetic properties of particles suspended in water and the presence of organic compounds in water. A revision of Volume 2 of Systems and Specifications of the Steel Structures Painting Manual was prepared, and the feasibility of protecting steel temporarily by depositing small amounts of metallic zine on bare metal surfaces by shot-blasting was examined. An investigation of the damaging effects of light on art objects and of new mothods for technical examination of museum objects continued; several reviews of the literature were published.

Under "Structure and Properties of Organic Materials" reference is made to a kinetic study of the nucleocarbamoylpyridinium ion and to the ring-opening reaction of dimethylcarbamoylpyridinium chloride with hydroxide ion to give a compound which afterwards decomposes to glutacondialdehyde; to the synthesis of the tetracyanodimethane derivative of dibenzopentalenoquinone, which forms deeply coloured salts with amines; to the synthesis of turneforcidene and hastanecine and their identification with the basic nitrogenous fragments obtained by cleavage of Senecio alkaloids; and to the identification of hydrocarbons obtained by heating $1: 2: 6$-cyclononatriene. Further work on the thermal degradation of wet marine muds has demonstrated the formation of benzene, thiophen, styrene and possibly methylthiophen, in addition to the toluene and $m$-xylene known to arise from the carotenoid components. Since phenylalanine yields benzene, toluene, styrene and other products, it may be a natural precursor of these aromatic hydrocarbons. Investigations of petroleum asphaltenes in the bending region of the infra-red have indicated the existence of four distinct absorption bands, and an extension of the dryfiltration theory has provided a reliable means for specifying requirements of filter media based on the electrostatic contributions of both the fabric and the collected particulate matter.
Considerable information was obtained during the year on internal motions in radicals by examining details of their electron spin resonance patterns, while the Bendix Time-of-Flight mass spectrometer has proved very suitable for examining ionization reactions occurring with electrons of less than several thousand electron volts energy. A series of cyclic dienes and their diepoxides has been synthesized for cyclopolymerization investigations of dicyclic compounds; light-scattering and viscosity examinations of a series of linear polystyrenes of narrow molecular weight distribution between $10^{\circ}$ and $110^{\circ} \mathrm{C}$ in dilute solutions in decalin were almost completed. Light scattering and viscosity investigations of some poly(bisphenol- $A$-carbonate) fractions were undertaken, and a comparison was made of the crystallization kinetics of nylon 6 and nylon 66 in the light of recently developed concepts of crystallization. Search continued for improved weather- and corrosion-resistant coatings for building materials.

The viscoelastic behaviour of glass-forming materials is being examined and further mathematical analyses made on the theory of the free-vibration experiment for a linear viscoelastic material. The crystal structure of tetrahydro$p$-benzoquinone dehydrate has been determined and refined from three-dimensional Weissenberg data and an electron spectrometer further developed and used to investigate inelastic electron scattering. Experimental facilities for low-frequency internal rotation spectroscopy were greatly expanded, and work on internal rotation continued vigorously, while the procedure for obtaining accurate solutions of the molecular Schrödinger equation was improved. The measurement and interpretation of the electronic spectra of transition metal cyanide complexes were extended to all the known complex cyanides, and the presence of hydrophobic bonding in the quaternary ammonium halides in aqueous solution was investigated by electrical conductance, transference and viscosity measurements. Chemical and physical properties of a set of molten quaternary ammonium salts were investigated, as well as the electrical conductivity of acidic solids in ultra-high vacuum and the silica-alumina catalysed isomerization of cyclopropane and the heat capacity below liquid-helium temperature of a series of copper-zinc alloys.

\title{
MAGNETOSPHERE AND THE MARTIAN BLUE CLEARING
}

\author{
By Dr. RONALD BLUM \\ Department of Physics and the College, University of Chicago
}

$\mathrm{W}$ HEN Mars is observed in yellow or red light, surface details of the planet can be seen; however, in blue or ultra-violet light of wave-length $\lambda<4550 \AA$ one sees a uniformly hazy disk with occasional bright patches, which obscures surface details ${ }^{1}$. This blue haze, believed to be due to a 'violet layer' in the upper Martian atmosphere, has been observed to clear up for several days at a time, particularly near opposition, when the Earth is between Mars and the Sun. It has been suggested ${ }^{2}$ that the blue haze may be due to the ionizing effect of solar protons on the Martian atmosphere; the protons are deflected by the Earth's magnetic field when the two planets are in opposition. This hypothesis has been rejected by Sagan $^{3}$ on the grounds that: (1) $2-\mathrm{MoV}$ protons are required to produce molecular ions with the requisite absorption bands at an altitude of $150 \mathrm{~km}$ in the Martian atmosphere, whereas solar wind protons are of the order of $1 \mathrm{keV}$; (2) proton fluxes of $5 \times 10^{12} / \mathrm{cm}^{2}$-sec are needed-large compared to solar wind fluxes of the order of $10^{8} / \mathrm{cm}^{2}$-sec; (3) the magnetosphere is too small to produce the required shadow effect at Mars; (4) the dipole field falls off too rapidly to have any effect at Mars's radius.
A possible answer to objections (3) and (4) may be found in Michel's calculation of the Mach angle of the oblique hydromagnetic shock extending into the solar wind downstream of the magnetosphere. ${ }^{4}$. Typical values of the solar wind parameters yield a hydromagnetic Mach number of 6 , and a Mach angle of $8 \cdot 5^{\circ}-9 \cdot 5^{\circ}$ (the Mach cone is slightly asymmetrical). Thus, the region behind the shock, or' 'wake', would have the appearance of a circular cone with its apex at the Earth, and an apex angle of approximately $9^{\circ}$. The axis of the cone should actually lag the Earth-Sun line by about $5^{\circ}$ due to the orbital motion of the Earth. This is very suggestive when compared with the observation ${ }^{5}$ that the Martian blue clearing is not observed whenever Mars lies very far above or below the ecliptic at opposition. Thus it would seem that clearing is possible only when Mars passes through a cone of small angle the apex of which is at the Earth, and the axis of which is approximately along the Earth-Sun line.

If we assume that the Earth and Mars both lie in the ecliptic plane and have nearly circular orbits, we may roughly calculate how long it would take Mars to pass through the conical wake of the Earth. We let $R_{e}=$ the radius of the Earth's orbit; $R_{m}=$ the radius of Mars's 